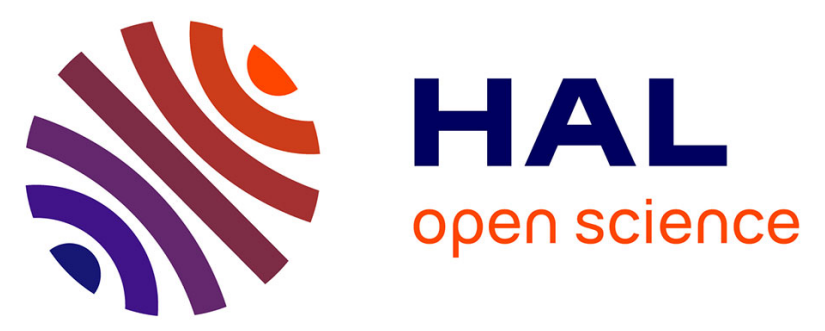

\title{
Ten-year analysis of the risk of severe outcomes related to low-dose glucocorticoids in early Rheumatoid Arthritis
}

\author{
Camille Roubille, Amandine Coffy, Nathalie Rincheval, Maxime Dougados, \\ René-Marc Flipo, Jean-Pierre Daurès, Bernard Combe
}

\section{To cite this version:}

Camille Roubille, Amandine Coffy, Nathalie Rincheval, Maxime Dougados, René-Marc Flipo, et al.. Ten-year analysis of the risk of severe outcomes related to low-dose glucocorticoids in early Rheumatoid Arthritis. Rheumatology, In press, 10.1093/rheumatology/keaa850 . hal-03079489

\section{HAL Id: hal-03079489 https://hal.science/hal-03079489}

Submitted on 30 Jul 2021

HAL is a multi-disciplinary open access archive for the deposit and dissemination of scientific research documents, whether they are published or not. The documents may come from teaching and research institutions in France or abroad, or from public or private research centers.
L'archive ouverte pluridisciplinaire HAL, est destinée au dépôt et à la diffusion de documents scientifiques de niveau recherche, publiés ou non, émanant des établissements d'enseignement et de recherche français ou étrangers, des laboratoires publics ou privés. 


\title{
Ten-year analysis of the risk of severe outcomes related to low-dose glucocorticoids in early rheumatoid arthritis
}

\author{
Camille Roubille ${ }^{1,2}$, Amandine Coffy ${ }^{3}$, Nathalie Rincheval ${ }^{3,4}$, Maxime \\ Dougados $^{5}$, René-Marc Flipo ${ }^{6}$, Jean-Pierre Daurès ${ }^{3}$ and Bernard Combe
}

\begin{abstract}
Objectives. To explore the 10-year tolerability profile of glucocorticoids (GC) use in patients with early RA. Methods. Analysis of 10-year outcome from the early arthritis ESPOIR cohort. Patients were stratified in two groups, without or with GC treatment at least once during their follow-up. The primary outcome was a composite of deaths, cardiovascular diseases (CVD), severe infections and fractures. The weighted Cox time-dependent analysis model was used with inverse probability of treatment weighting (IPTW) propensity score method.

Results. Among the 608 patients [480 women, mean age of 47.5 (12.1)years], 397 (65\%) received low-dose GC [median $1.9 \mathrm{mg}$ /day (IQR 0.6-4.2), mean cumulative prednisone dose $8468 \mathrm{mg}$ (8376), mean duration 44.6 months (40.1)]. In univariate analysis, over 95 total events (10 deaths, 18 CVDs, 32 fractures and 35 severe infections), patients taking GC experienced more events $(n=71)$ than those without $\mathrm{GC}(n=24)(P=0.035)$. Highest cumulative exposure of $\mathrm{GC}$ $(\geq 8.4 \mathrm{~g})$ was associated with highest risk of occurrence of the primary outcome $(24.3 \%, P=0.007)$, CVDs $(7.9 \%$, $P=0.001)$ and severe infections $(9.9 \%, P=0.024)$. The risk of events over time was significantly associated with $\mathrm{GC}$, age, hypertension and ESR. The risk associated with GC treatment increased between the first follow-up visit [hazard ratio $(\mathrm{HR})$ at 1 year $=0.46,95 \% \mathrm{Cl}: 0.23,0.90]$ and 10 years $(\mathrm{HR}=6.83,95 \% \mathrm{Cl}: 2.29,20.35)$.

Conclusion. The 10-year analysis of this prospective early RA cohort supports a dose and time-dependent impact of low-dose GC treatment, with a long-term high risk of severe outcomes.
\end{abstract}

Trial registration. (ClinicalTrials.gov Identifier: NCT03666091).

Key words: rheumatoid arthritis, early arthritis, glucocorticoids, safety outcomes

\section{Rheumatology key messages}

- Highest cumulative exposure of glucocorticoids (GC) was associated with highest risk of occurrence of severe outcomes.

- The risk associated with $\mathrm{GC}$ increased between 1 year $(\mathrm{HR}=0.46,95 \% \mathrm{Cl}: 0.23,0.90)$ and 10 years $(\mathrm{HR}=6.83$, 95\% Cl: 2.29, 20.35).

- Low-dose GC treatment may have a dose and time-dependent long-term high risk of severe outcomes in RA.

\footnotetext{
${ }^{1}$ Department of Internal Medicine, CHU Montpellier, Montpellier University, ${ }^{2}$ PhyMedExp, University of Montpellier, INSERM U1046, CNRS UMR 9214, Montpellier, ${ }^{3}$ Statistiques, University Institute of Clinical Research EA2415 and Clinique Beausoleil, Montpellier cedex, ${ }^{4}$ Rheumatology Department, CHU Montpellier, Montpellier University, Montpellier, ${ }^{5}$ Medicine Faculty and Rheumatology B Department, Paris-Descartes University, UPRES-EA 4058; APHP, Cochin Hospital, Paris and 'Department of Rheumatology, Roger Salengro Hospital, Lille, France

Submitted 20 September 2020; accepted 14 November 2020
}

Correspondence to: Bernard Combe, Department of Rheumatology, $\mathrm{CHU}$ Montpellier and University of Montpellier, Hôpital Lapeyronie, 371 Avenue du Doyen Gaston Giraud, 34295 Montpellier cedex 5, France. E-mail: b-combe@chu-montpellier.fr

\section{Introduction}

Glucocorticoids (GC) remain an essential part of the therapeutic strategy in RA [1], especially in early RA [2]. They offer rapid relief of the patient's symptoms and a lasting reduction in disease activity, while having some beneficial structural effects [3]. GCs appear to be widely used in $\sim 50 \%$ of patients with RA [4], with varied duration and dosage among the studies. However, taking a balanced position on the place of GCs in RA management is not easy, as we are always torn between its efficacy and its deleterious effects. Benefit/risk ratio is currently still controversial. It was argued that the risk of 
harm from low-dose GC was sufficiently low for most patients receiving long-term doses of $\leq 5 \mathrm{mg}$ prednisone equivalent per day [5]. Actually, there is little evidence of safety [6], particularly with regard to the long-term use of $\mathrm{GC}$ at low doses. Therefore, recent international guidelines continue to indicate the use of short-term GCs, which should be tapered as rapidly as clinically feasible [2, 7]. The critical question remains as to whether this low-dose regimen is actually of low toxicity while still being effective.

In the Etude et Suivi des POlyarthrites Indifférenciées Récentes (ESPOIR) cohort [8], more than half of patients received GC at least once within 5 years of inclusion [9], allowing the identification of incident events occurring after GC initiation. An interim 7-year analysis did not show a significant difference with regard to severe outcomes between recent onset RA patients taking or not low-dose GC [10], possibly due to insufficient number of events or too short follow-up time.

\section{Objective}

In the present study, we aimed to explore the 10-year tolerability profile of GC use in early RA patients in the ESPOIR cohort, by investigating the relationship between GC use and all-cause mortality, cardiovascular diseases (CVDs), severe infections and bone fractures.

\section{Patients and methods}

\section{Study design and setting}

The ESPOIR cohort is a prospective multicentre observational cohort that included patients with early arthritis from 14 rheumatology centres in France. Patients had to have inflammatory arthritis in at least two swollen joints lasting from 6 weeks to 6 months, with the potential to develop into RA, and be naïve to DMARDs and GC therapy. Patients with disease meeting criteria for a definite diagnosis other than RA or exhibiting features that ruled out progression to RA were excluded [8]. A total of 813 patients have been included between 2002 and 2005 . The objective, design and characteristics of the cohort were previously described $[9,11]$ (supplementary methods, available at Rheumatology online). All patients gave their signed informed consent before inclusion. Treatment of patients was at the discretion of the treating physician, and investigators at the cohort centres were simply collecting data without giving recommendations. The protocol of the ESPOIR cohort and of this study was approved by the ethics committee of Montpellier, France (No. 020307). All the data of the ESPOIR cohort are available after approval by the scientific committee (www.lacohorteespoir.fr).

\section{Patients and GC use}

Among the 813 included patients, we selected the 720 who fulfilled the 2010 American College of Rheumatology/European League Against Rheumatism criteria for RA over the 10 years of follow-up. We excluded patients with missing data for GC treatment and those not followed up to 1 year. We then excluded patients with a past history at baseline of CVD, severe infection or bone fracture because these patients might have a different profile for the prescription of $G C$ and risk of related side effects; we first examined data for these 608 patients with RA (population 1). Then, we also analysed data for 670 patients including the 62 patients with a past history of CVD, severe infections or fractures (population 2) (Fig. 1).

Selected patients were classified into two groups based on whether or not they received GC at least once over the 10-year follow-up period. The GC group included patients who received systemic GC therapy (oral, intramuscular or intravenous) at least once between inclusion and the end of follow-up. The non-GC group included patients who never took a GC between inclusion and the end of follow-up. GC use was defined as use (yes or no) when the first safety event occurred. Doses were calculated as prednisone-equivalent based on accepted standards.

Patients were not involved in the design, or conduct, or reporting or dissemination plans of our study. Once the study has been published, participants will be informed of the results through a dedicated information letter.

\section{Variables and outcomes}

The primary outcome was a composite of new-onset safety events including all-cause mortality, CVDs (myocardial ischaemia, stroke and heart failure), severe infections and bone fractures (declarative data that were verified in the patient's medical record). Secondary outcomes included each of these components. We have selected these four types of adverse effects of GC therapy to cover those of greatest concern [12]. For each patient, if more than one event occurred, only the first event was counted. Causes of deaths were assessed using CépiDC, the French national registry of specific causes of mortality. A variable named 'cardiovascular risk' was created to account for the presence of at least one cardiovascular risk factor among hypertension, hypercholesterolaemia, BMl $>30 \mathrm{~kg} / \mathrm{m} 2$, diabetes and smoking. Severe infection was defined as requiring hospitalisation or intravenous antibiotics.

\section{Statistical analysis}

Descriptive statistics are presented as mean (S.D.) or number (\%) where appropriate. The non-parametric Mann-Whitney $U$ test was used to compare the distribution of continuous variables and $\chi^{2}$ test (or Fisher's exact test) to test the association of categorical variables. Continuous variables were transformed into categorical variables with the median or a predetermined threshold. The $P$-values $<0.05$ were considered significant and all statistical tests were two-sided. The composite primary outcome and each of its components 
Fig. 1 Study design

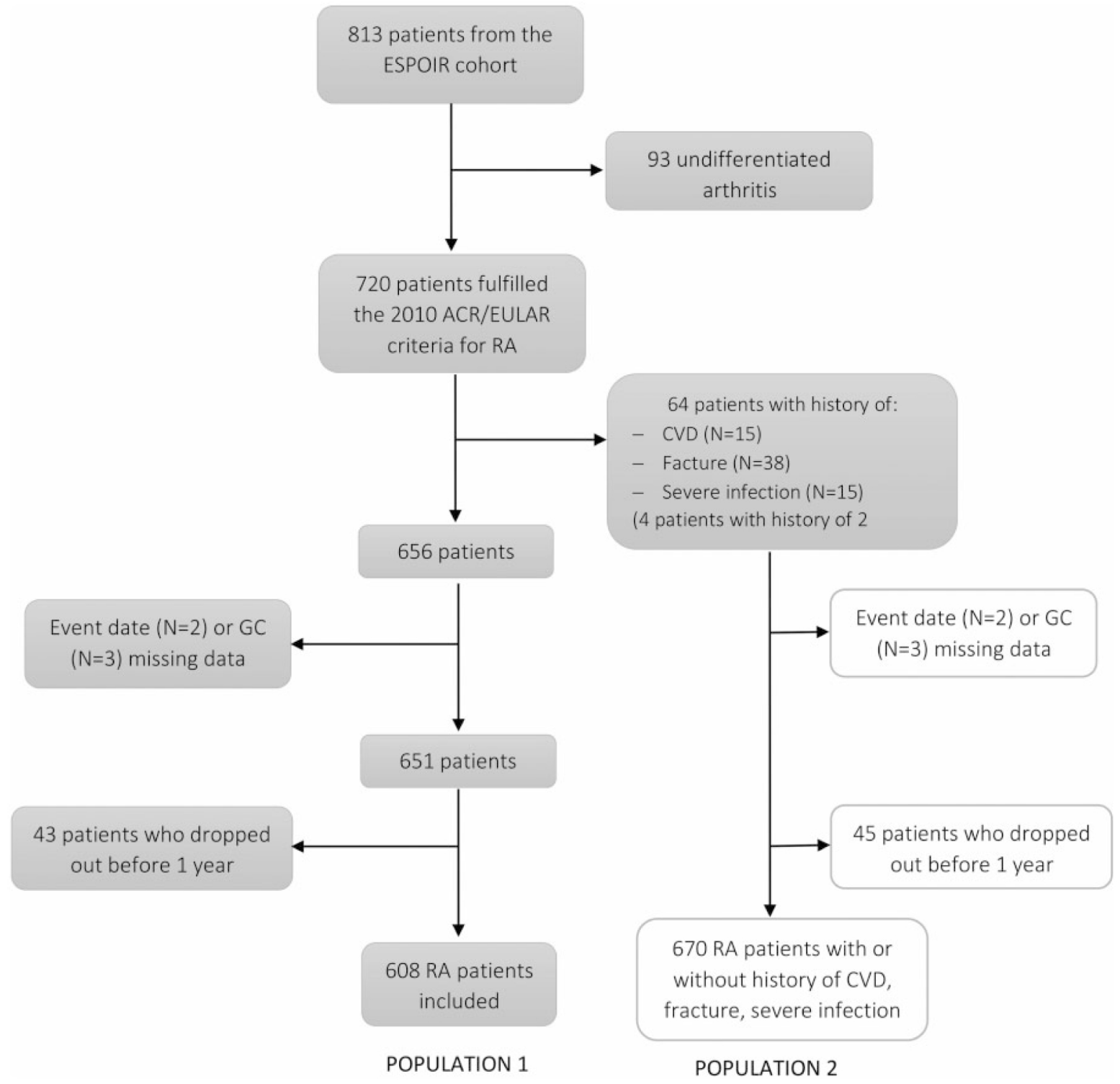

CVD: cardiovascular diseases (myocardial ischaemia, stroke and heart failure); ESPOIR: Etude et Suivi des POlyarthrites Indifférenciées Récentes; GC: glucocorticoids.

were compared by $\chi^{2}$ test (or Fisher's exact test) on univariate analysis. Thereafter, Cox proportional hazards regression was used to assess the association between GC treatment and outcome, estimating hazard ratios (HRs) and 95\% Cls. To reduce the impact of treatment selection bias and potential confounding, the weighted Cox proportional hazards model was used with inverse probability of treatment weighting (IPTW) [13]. With this method, weights for patients who had and patients who had not received GC were the inverse of 'propensity score' (PS) and the inverse of '1-PS', respectively. The PS is defined as the predicted patient's probability of receiving GC, conditional on a set of observed baseline covariates. The PS was estimated by multiple logistic regression analysis. Two sets of observed baseline covariates were included in the PS model available at Rheumatology online) [14]. The first set of covariates, selected by using the log-rank test, was related to the outcome and the second set, selected using $\chi^{2}$ test, was related to GC treatment. For both long-rank and $\chi^{2}$ tests, the level of significance was set at $P<0.15$. In addition, we used three procedures for selecting variables (forward, backward and stepwise), all procedures led to the same model. The PS was then included in the Cox proportional-hazards model with the baseline covariates that were significant at 15\% on the log-rank test and not already included in the PS model. Furthermore, because the proportional hazard assumption was not verified for GC treatment (yes or no), a time-by-covariate interaction was created to check if GC 
treatment hazard ratios vary with time. Graphs showing the evolution over time of the HR $(95 \% \mathrm{Cl})$ of $\mathrm{GC}$ treatment were made.

In the sensitivity analysis of the 670 patients, comprising the patients without and with a past-history at baseline of CVD, severe infection or fracture and sufficient data, the methodology was similar. The two sets of covariates included in the PS model were the same as in the principal analysis, with, in addition, the covariate past-history at baseline of CVD, severe infection or fracture. As with the first population analysis, a time-bycovariate interaction was created for GC treatment.

Furthermore, the original studied population could be considered different subgroups on the basis of the cumulative GC dose and total duration of GC treatment over 10 years. These two variables were transformed into a two then three-level categorical variable by median and quartiles. First, the log-rank test was used to assess the effect of those new covariates. Then, Cox models with time-by-covariate interaction for GC treatment were carried out. $P$-value $<0.05$ was considered to be statistically significant and all statistical tests were two-sided. Statistical analyses involved use of SAS version 9.4 (SAS Institute, Cary, NC, USA).

\section{Results}

\section{Study population}

The study population (population 1) comprised 608 RA patients, including 480 women, mean age of 47.5 (12.1)years. Mean duration of follow-up was 8.66 (2.58) years [median 9.97years (IQR 9.01-10.02)], 441 patients had a 10 -year visit. Baseline characteristics of this population are presented in Table 1. Most of patients had moderate to high disease activity, with $43.4 \%$ of them being anti-citrullinated protein antibodies (ACPA) positive. In total, 397 patients $(65.3 \%)$ received low-dose GC, mainly started during the first 6 months $(70 \%)$. The mean dose over the entire follow-up was 2.8 (2.8) $\mathrm{mg} / \mathrm{d}$ (median $1.9 \mathrm{mg} /$ day (IQR 0.6-4.2)) and the mean dose over the duration of use was $9.0 \mathrm{mg} / \mathrm{d}(9.6)$ [median $6.3 \mathrm{mg} / \mathrm{d}$ (IQR 4.9-8.6)]. The mean duration of GC treatment was 44.6 months (40.1), and the mean cumulative GC dose was $8468 \mathrm{mg}$ (8376) [median $5646 \mathrm{mg}$ (IQR 1940-13 022)]. Among the 397 patients who received GC during follow-up, 55\% received GC for $>2$ years; 47 (11.8\%) patients received GC for up to 9 years. GC patients had more active disease at baseline, with higher DAS28-CRP and HAQ scores, higher ACPA levels, and consumed more NSAIDs and more biologic agents or DMARDs during follow-up.

Association between GC use and composite of death, CVD, severe infections and fractures

Overall, on the study population, 95 events were identified during follow-up: 10 deaths, 18 CVDs, 32 fractures and 35 severe infections. Deaths were related to myocardial infarction $(n=1)$, cancer or malignant blood diseases $(n=6)$, multi-system organ failure $(n=1)$, rupture of oesophageal varices $(n=1)$, natural death $(n=1)$.

Based on univariate analysis at 10 years, patients taking GC experienced significantly more events $(n=71)$ than those without $\mathrm{GC}(n=24)(P=0.035)$, particularly severe infections ( $n=30$ with $\mathrm{GC}$ vs 5 without $\mathrm{GC}, P=0.009$ ) (Table 2). Interestingly, we found a significant cumulative dose effect on the primary outcome $(P=0.007)$, CVDs $(P=0.001)$ and severe infections $(P=0.024)$ (Table 3$)$. Highest cumulative exposure of GC was associated with highest risk of occurrence of the primary outcome. Indeed, among patients who received a cumulative dose $>8.4 \mathrm{~g}$ of prednisone during follow-up, $24 \%$ experienced the primary outcome, with almost $8 \%$ having a CVD and almost $10 \%$ a severe infection (Table 3 ). We found no significant difference between groups with or without events based on the number of biologic DMARDs $(P=0.40)$ or on the duration of biologic DMARDs $(P=0.54)$.

Next, to account for potential confounding by indication, we used a PS. The baseline covariates retained in the final PS regression model were: ACPA, diabetes, $\mathrm{HAQ}$ Disability Index (HAQ-DI) score, cardiovascular risk, patient's overall assessment using visual analogue scale and osteoporosis

The PS was then included in the Cox proportional-hazards model with the baseline covariates that were significant at $15 \%$ on the log-rank test and not already included in the PS model: age, gender, history of hypertension, ESR, CRP, RF-IgA.

On weighted Cox time-dependent analysis, using the IPTW propensity score method, the risk of events over time was significantly associated with GC treatment $(P<0.001)$, age, history of hypertension and ESR. Importantly, the risk associated with GC treatment increased between the first follow-up visit: hazard ratio $(\mathrm{HR})$ at 1 year $=0.46,95 \% \mathrm{Cl}: 0.23,0.90$ and 10 years ( $\mathrm{HR}=6.83,95 \% \mathrm{Cl}: 2.29,20.35)$ (Fig. 2).

In the sensitivity analysis on the 670 patients with or without a past-history (population 2), over 109 events (13 deaths, 24 CVDs, 34 fractures and 38 severe infections), patients taking GC also experienced more events ( $n=81)$ than those without GC $(n=28)$ (univariate analysis, $P=0.029$ ), especially severe infections $(n=32$ with $\mathrm{GC}$ vs 6 without $\mathrm{GC}, P=0.011$ )

The baseline covariates retained in the PS regression model for this analysis were almost the same (except for cardiovascular risk), plus smoker and tender joint count

The PS was then included in the Cox proportional-hazards model with age, gender, history of hypertension, history of CVD, severe infection or fracture, RF, ESR. The risk of events over time was again significantly associated with GC treatment $(P<0.001)$, age, history of hypertension and gender. Again, the risk associated with GC increased between the first follow-up visit and 10 years $(\mathrm{HR}=6.72,95 \%$ Cl: $2.41,18.73$ ) 
TABLE 1 Baseline demographic, clinical, biological and radiographic characteristics of the study population from the ESPOIR cohort $(n=608)$ and those without and with glucocorticoids (GC)

\begin{tabular}{|c|c|c|c|c|c|}
\hline & $n$ & $\begin{array}{l}\text { Total study } \\
\text { population } \\
(n=608)\end{array}$ & $\begin{array}{c}\text { Without GC } \\
(n=211)\end{array}$ & With GC ( $n=397)$ & $P_{\text {-value }}{ }^{a}$ \\
\hline Age, mean (s.D.), years & 608 & $47.5(12.1)$ & $48(11.9)$ & $47.3(12.3)$ & 0.634 \\
\hline Female, $n(\%)$ & 608 & $480(78.9)$ & $173(82)$ & $307(77.3)$ & $0.180^{\mathrm{b}}$ \\
\hline BMI, mean (s.o.), $\mathrm{kg} / \mathrm{m}^{2}$ & 606 & $25(4.6)$ & $25(4.5)$ & $25(4.6)$ & 0.919 \\
\hline $\mathrm{BMI}>30 \mathrm{~kg} / \mathrm{m}^{2}, n(\%)$ & 606 & $83(13.7)$ & $28(13.3)$ & $55(13.9)$ & $0.823^{b}$ \\
\hline Diabetes, $n(\%)$ & 608 & $19(3.1)$ & $12(5.7)$ & $7(1.8)$ & $0.008^{b}$ \\
\hline Hypertension, $n(\%)$ & 608 & $98(16.1)$ & $31(14.7)$ & 67 (16.9) & $0.486^{b}$ \\
\hline Hypercholesterolemia, $n(\%)$ & 608 & $85(14)$ & $25(11.8)$ & $60(15.1)$ & $0.269^{b}$ \\
\hline Smokers, $n(\%)$ & 608 & $296(48.7)$ & $84(39.8)$ & $212(53.4)$ & $0.001^{b}$ \\
\hline $\begin{array}{l}\text { Hypertension or hypercholesterolemia or diabetes } \\
\text { or } \mathrm{BMI}>30 \text { or smoker, } n(\%)\end{array}$ & 608 & $407(66.9)$ & $128(60.7)$ & $279(70.3)$ & $0.016^{b}$ \\
\hline $\begin{array}{l}\text { At least one DMARD treatment from baseline to } \\
10 \text { years, } n(\%)\end{array}$ & 608 & $549(90.3)$ & $176(83.4)$ & $373(94)$ & $<0.001^{b}$ \\
\hline $\begin{array}{l}\text { At least one biological agent from baseline to } \\
10 \text { years, } n(\%)\end{array}$ & 608 & $181(29.8)$ & $37(17.5)$ & $144(36.3)$ & $<0.001^{b}$ \\
\hline Consumption of NSAIDs, $n(\%)$ & 608 & $547(90)$ & $179(84.8)$ & $368(92.7)$ & $0.002^{\mathrm{b}}$ \\
\hline DAS28-CRP, mean (S.D.) & 597 & $5.2(1.3)$ & $4.8(1.1)$ & $5.3(1.3)$ & $<0.001$ \\
\hline DAS28-CRP, $n(\%)$ & 597 & & & & $0.001^{b}$ \\
\hline$\leq 2.6$ & & $13(2.2)$ & $9(4.4)$ & $4(1.0)$ & \\
\hline $2.6-3.2$ & & $24(4.0)$ & $7(3.4)$ & $17(4.3)$ & \\
\hline $3.2-5.1$ & & $258(43.2)$ & $105(51.0)$ & $153(39.1)$ & \\
\hline$>5.1$ & & $302(50.6)$ & $85(41.3)$ & $217(55.5)$ & \\
\hline HAQ score, mean (s.D.) & 608 & $1(0.7)$ & $0.8(0.6)$ & $1.1(0.7)$ & $<0.001$ \\
\hline $\mathrm{HAQ}, n(\%)$ & 608 & & & & $<0.001^{b}$ \\
\hline$\leq 0.5$ & & $189(31.1)$ & $86(40.8)$ & $103(25.9)$ & \\
\hline$>0.5$ & & 419 (68.9) & $125(59.2)$ & $294(74.1)$ & \\
\hline CRP, mean (s.D.), mg/l & 608 & $19.8(32.8)$ & $13.7(22.3)$ & $23.1(36.8)$ & $<0.001$ \\
\hline CRP level > $10 \mathrm{mg} / \mathrm{l}, n(\%)$ & 608 & $276(45.4)$ & $77(36.5)$ & $199(50.1)$ & $0.001^{b}$ \\
\hline RF, mean (s.D.), Ul/ml & 608 & $120.4(443.5)$ & $113(503.8)$ & $124.4(408.6)$ & 0.050 \\
\hline IgM-RF positivity, $n$ (\%) & 608 & $317(52.1)$ & $101(47.9)$ & $216(54.4)$ & $0.124^{b}$ \\
\hline ACPA, mean (S.D.), Ul/ml & 608 & $510.1(1329.8)$ & $342.7(1040.8)$ & $599.1(1453.7)$ & $<0.001$ \\
\hline ACPA positivity, $n(\%)$ & 608 & $264(43.4)$ & $70(33.2)$ & $194(48.9)$ & $<0.001^{b}$ \\
\hline Typical erosion, $n(\%)$ & 575 & $153(26.6)$ & $53(26.8)$ & $100(26.5)$ & $0.950^{\mathrm{b}}$ \\
\hline vSHS score, mean (S.D.) & 580 & $5.4(7.7)$ & $5.9(8.3)$ & $5.1(7.4)$ & 0.203 \\
\hline
\end{tabular}

Data are $n$ (\%) or mean (S.D.). P-values were assessed by ${ }^{a}$ Mann-Whitney test and ${ }^{b}$ chi-square test (or Fisher's exact test). ACPA: anti-citrullinated protein antibodies; DAS28-CRP: Disease Activity Score in 28 joints, with CRP level; IgM: immunoglobulin M; mSHS: van der Heijde-modified Sharp score.Bold p-values are statistically significant values.

TABLE 2 Primary outcome at 10 years (death, cardiovascular disease, severe infection or fracture) in the total sample and with and without glucocorticoid (GC) (univariate analysis)

\begin{tabular}{lcrrr}
\hline & Total study population $(\boldsymbol{n}=\mathbf{6 0 8})$ & Without GC & With GC & P-value \\
\hline Primary outcome, $n(\%)$ & $95(15.6 \%)$ & $24(11.4 \%)$ & $71(17.9 \%)$ & 0.035 \\
Death, $n(\%)$ & $10(1.6 \%)$ & $1(0.5 \%)$ & $9(2.3 \%)$ & 0.103 \\
Cardiovascular diseases, $n(\%)$ & $18(3 \%)$ & $3(1.4 \%)$ & $15(3.8 \%)$ & 0.177 \\
Severe infections, $n(\%)$ & $35(5.8 \%)$ & $5(2.4 \%)$ & $30(7.6 \%)$ & 0.009 \\
Fractures, $n(\%)$ & $32(5.3 \%)$ & $15(7.1 \%)$ & $17(4.3 \%)$ & 0.137 \\
\hline
\end{tabular}

\section{Discussion}

In the present study, we aimed to determine the longterm adverse events of low-dose GC treatment in the
ESPOIR cohort. We report that the risk associated with low-dose GC increases with time, becoming significant after 6 years with a maximum by 10 years. These findings argue for a delayed harmfulness of low-dose GC, 
TABLE 3 Primary outcome at 10 years (death, cardiovascular disease, severe infection or fracture) depending on the cumulative dose of glucocorticoid (GC) (univariate analysis)

\begin{tabular}{|c|c|c|c|c|c|c|c|c|c|}
\hline & \multicolumn{8}{|c|}{ Cumulative dose of GC treatment (mg): quartiles } & \multirow[t]{3}{*}{$P$-value } \\
\hline & \multicolumn{2}{|c|}{$\mathbf{0}$} & \multicolumn{2}{|c|}{ [0-1842] } & \multicolumn{2}{|c|}{ [1842-8421.5] } & \multicolumn{2}{|c|}{$>=8421,5$} & \\
\hline & $n=211$ & $\%$ & $n=93$ & $\%$ & $n=152$ & $\%$ & $n=152$ & $\%$ & \\
\hline Primary outcome & 24 & $11.4 \%$ & 13 & $14.0 \%$ & 21 & $13.8 \%$ & 37 & $24.3 \%$ & 0.007 \\
\hline Cardiovascular diseases & 3 & $1.4 \%$ & 2 & $2.2 \%$ & 1 & $0.7 \%$ & 12 & $7.9 \%$ & 0.001 \\
\hline Death & 1 & $0.5 \%$ & 1 & $1.1 \%$ & 4 & $2.6 \%$ & 4 & $2.6 \%$ & 0.248 \\
\hline Fractures & 15 & $7.1 \%$ & 5 & $5.4 \%$ & 6 & $3.9 \%$ & 6 & $3.9 \%$ & 0.475 \\
\hline Severe infections & 5 & $2.4 \%$ & 5 & $5.4 \%$ & 10 & $6.6 \%$ & 15 & $9.9 \%$ & 0.024 \\
\hline
\end{tabular}

which increases with the cumulative dose, especially with regard to CVDs and severe infections. This may explain, in addition to the lower power linked to the reduce number of events, that our 7-year interim analysis did not find a significant difference with respect to severe outcomes between patients taking or not low-dose GC [10].

GC therapy has been associated with well-known toxicities, particularly at high doses. By contrast, with respect to low-dose GC, the evidence appears to be more controversial. A systematic review highlighted the lack of data on the association between low-dose GC and risk of infection [15]. A meta-analysis has shown that GCs significantly increase CVDs (RR, 1.47; $95 \% \mathrm{Cl}$ : $1.34,1.60)[16]$. Importantly, more than the low dose itself, it may rather be the cumulative dose that has the most impact. In our results, the cumulative dose was significantly associated with both CVDs and severe infections, with $24 \%$ of patients taking more than the mean cumulative dose of $8.4 \mathrm{~g}$ experiencing the primary outcome. This mean cumulative dose is equivalent to taking $\sim 5 \mathrm{mg} /$ day during 5 years, which seems very common. However, to date, it seems that the benefit/ risk ratio of low-dose GC in RA has been perceived as positive, with an assumed overestimated level of toxicity $[17,18]$. Nevertheless, strong evidence on the risk of harm of long-term use of low-dose GC treatment remains quite limited [1].

On the one hand, based on RCTs, the safety profile of low-dose GC appears to be relatively mild and hardly different from that of placebo [3, 17, 19, 20]. Indeed, some RCTs argue that short-term treatment with high to moderate doses of GC in early RA is effective and may be considered safe [21-23], although long-term safety data are scarce.

Long-term post-trial analysis (median follow-up nearly 7 years) of the Computer Assisted Management in Early RA (CAMERA II), in which patients with early RA received prednisone at $10 \mathrm{mg} /$ day for at least 2 years, showed no significant difference in GCs-related comorbidities. However, although not significant, increase of CVD and mortality risk was evidenced in patients receiving GCs [24]. In the Better Anti-Rheumatic PharmacOTherapy (BARFOT) study, low-dose prednisolone $(7.5 \mathrm{mg} /$ day) use in early RA, was associated with longterm increased incidence of CVD and a trend towards increased mortality [25].

On the other hand, high-quality long-term observational studies, using statistical methods, that allow to minimize confounding by indication, may help to explore GC safety profile in real-life settings. For instance, Dixon et al. reported an increased risk of infection in association with low-dose GC in patients aged over 65 [26], contrasting with no significant difference from placebo based on the RCTs [27]. Highest cumulative exposure of GCs have been associated with increased risk of CVD [28].

The limitations of the present study include those that cannot be ignored in observational cohort studies, with potential confounding factors that could not be taken into account. Moreover, most data regarding comorbidities were declarative, with potential recall bias. Finally, we used a composite end point. However, we found enough events to show some significance for individual end point such as CVDs and severe infections.

Our study has a number of strengths. The ESPOIR cohort allows exploration of the time-dependent tolerance profile of GC in early RA, in a real-world setting, providing long follow-up time with a low rate of missing data or drop-out. Besides, to reduce the indication bias, we used a PS to ensure the association between GC and outcomes is as relevant as possible. Indeed, patients with more severe arthritis are more likely to receive GC, which artificially leads to more adverse events [29]. Here, given that GC patients had more active disease, higher ACPA levels, and consumed more NSAIDs and more biologic or synthetic DMARDs, using a PS to reduce confounding by indication appears clinically relevant.

In summary, this 10-year data analysis of low-dose GC in the ESPOIR cohort revealed a significant timedependent risk of severe outcomes, including CVDs and severe infections. These results support a long-term incidence of serious adverse events that warrant 
FiG. 2 Time-dependent relationship between glucocorticoids treatment and risk of severe adverse events estimated by hazard ratio $(\mathrm{HR})$

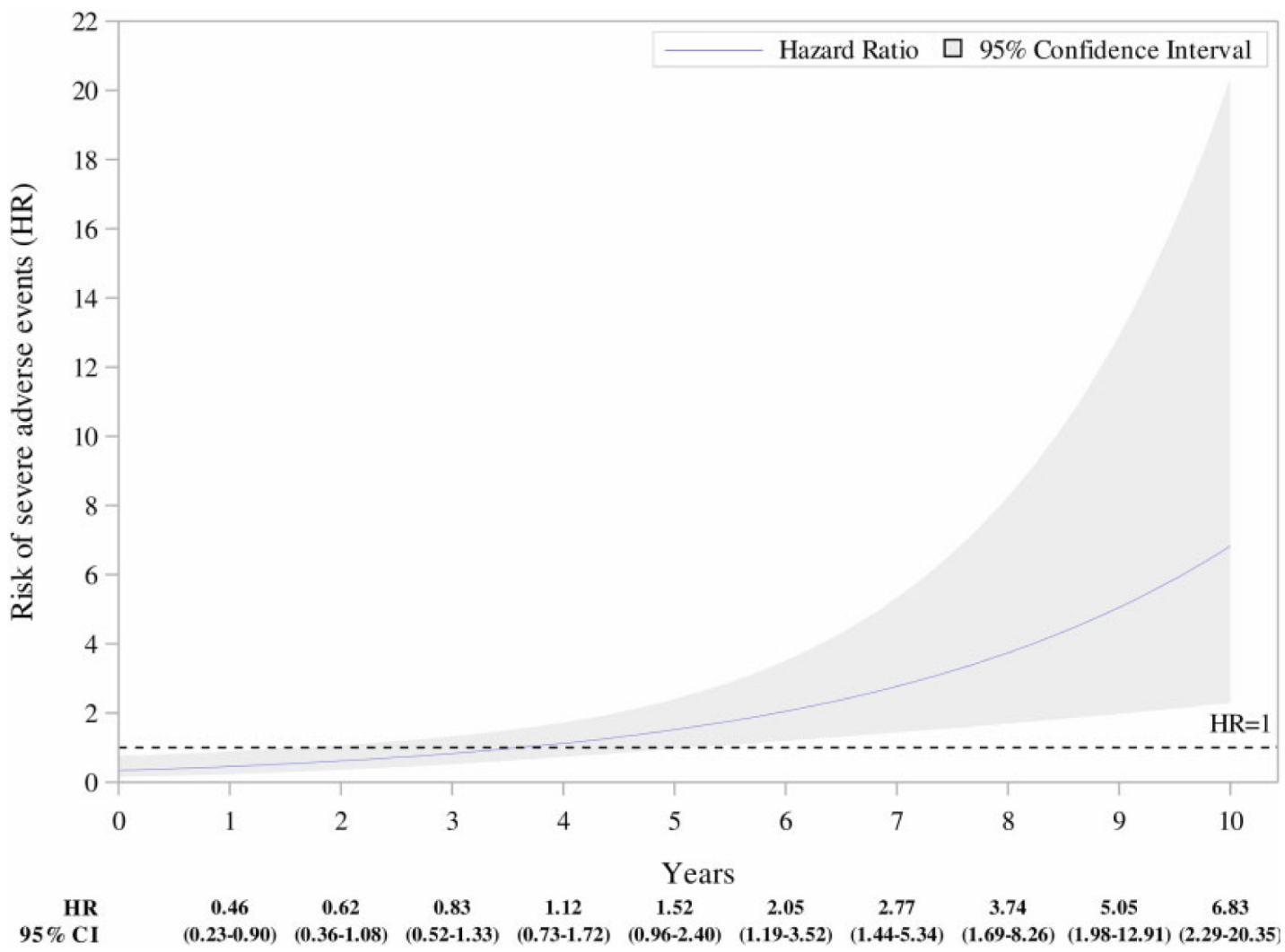

integrated and sustained screening and management of GC-related complications in RA patients. Therefore, according to our results, the current expert consensus that GCs should be used at the lowest possible dose and for the shortest duration comes to full sense.

A second topic scarcely considered by any guideline to date is the potential influence of patient-specific factors on the optimal treatment regimen. This is a significant deficit that should be addressed, as patientspecific factors like comorbidities, co-medications, or other (relative) contra- indications are of crucial importance in guiding glucocorticoid therapy in individual patients.

\section{Acknowledgement}

We are grateful to the investigators who recruited and followed the patients (F. Berenbaum, Paris-Saint Antoine; MC. Boissier, Paris-Bobigny; A. Cantagrel, Toulouse; B. Combe, Montpellier; M. Dougados, ParisCochin; P. Fardellone and P. Boumier, Amiens; B. Fautrel, Paris-La Pitié; RM. Flipo, Lille; Ph. Goupille, Tours; F. Liote, Paris- Lariboisière; O. Vittecoq, Rouen; X. Mariette, Paris-Bicêtre; P. Dieude, Paris Bichat; A. Saraux, Brest; T. Schaeverbeke, Bordeaux; and J. Sibilia, Strasbourg). All authors had full access to the data and reviewed and approved the manuscript for publication. B.C. takes responsibility for the integrity of the data and the accuracy of the data analysis. Concept and design: C.R., B.C., N.R., J.-P.D. Acquisition, analysis, or interpretation of data: all authors. Drafting of the manuscript: C.R., B.C. Critical revision of the manuscript: all authors. Agreement to be accountable for all aspects of the work: all authors. Statistical analysis: A.C., N.R., J.-P.D. Obtained funding: C.R., B.C.

Transparency declaration: The lead author (the manuscript's guarantor) affirms that the manuscript is an honest, accurate, and transparent account of the study being reported; that no important aspects of the study have been omitted; and that any discrepancies from the study as planned (and, if relevant, registered) have been explained.

The Corresponding Author has the right to grant on behalf of all authors and does grant on behalf of all authors, a worldwide licence to the Publishers and its licensees in perpetuity, in all forms, formats and media (whether known now or created in the future), to i) publish, reproduce, distribute, display and store the Contribution, ii) translate the Contribution into other languages, create adaptations, reprints, include within collections and create summaries, extracts and/or, abstracts of the Contribution, iii) create any other derivative work(s) based on the Contribution, iv) to exploit all 
subsidiary rights in the Contribution, v) the inclusion of electronic links from the Contribution to third party material where-ever it may be located; and, vi) licence any third party to do any or all of the above.

Funding: The ESPOIR cohort is sponsored by the French Society for Rheumatology. An unrestricted grant from Merck Sharp and Dohme (MSD) was allocated for the first 5 years. Two additional grants from INSERM were obtained to support part of the biological database. Pfizer, Abbvie, and Lilly also supported the ESPOIR cohort.

Disclosure statement: All authors have completed the ICMJE uniform disclosure form at www.icmje.org/coi_dis closure.pdf and declare as follows. C.R.: received a grant (2838) from the French Society for Rheumatology (SFR), and received honoraria from Servier and Pfizer. A.C.: No competing interest. N.R.: No competing interest. M.D.: has participated at advisory boards and/or symposium organized by Pfizer, Abbvie, Lilly, UCB, Merck, BMS, Roche, Biogen, Sanofi, Novartis, Sandoz and his department has received research grants from Pfizer, Abbvie, Lilly, UCB, Merck, BMS, Roche, Biogen, Sanofi, Novartis, Sandoz. R.-M.F.: received honoraria from Abbvie, Biogen, BMS, Janssen, MSD, Nordic, Novartis, Pfizer, Roche-Chugai and Sanofi-Genzyme and grants from Abbvie, Janssen, Novartis, Pfizer and RocheChugai. J.-P.D.: No competing interest. B.C.: received honoraria from AbbVie; BMS; Gilead; Janssen; Lilly; Merck; Novartis; Pfizer; Roche-Chugai; Sanofi; and UCB; and research grants from Novartis, Pfizer, and Roche.

\section{Data availability statement}

Data are available upon reasonable request by any qualified researchers who engage in rigorous, independent scientific research, and will be provided following review and approval of a research proposal and Statistical Analysis Plan (SAP) and execution of a Data Sharing Agreement (DSA). All data relevant to the study are included in the article.

\section{References}

1 Hua C, Buttgereit F, Combe B. Glucocorticoids in rheumatoid arthritis: current status and future studies. RMD Open 2020;6:e000536.

2 Combe B, Landewe R, Daien Cl et al. 2016 update of the EULAR recommendations for the management of early arthritis. Ann Rheum Dis 2017;76:948-59.

3 Daien $\mathrm{Cl}$, Hua C, Combe B, Landewe R. Nonpharmacological and pharmacological interventions in for the management of early arthritis. RMD Open 2017;3: e000404.

4 Sokka T, Kautiainen $\mathrm{H}$, Toloza S et al. RA: quantitative clinical assessment of patients with rheumatoid arthritis seen in standard rheumatology care in 15 countries. Ann Rheum Dis 2007;66:1491-6.

5 Strehl C, Bijlsma JWJ, M de W et al. Defining conditions where long-term glucocorticoid treatment has an acceptably low level of harm to facilitate implementation of existing recommendations: viewpoints from an EULAR task force. Ann Rheum Dis 2016;75:952-7.

6 Santiago T, da Silva JAP. Safety of glucocorticoids in rheumatoid arthritis: evidence from recent clinical trials. Neuroimmunomodulation 2015;22:57-65.

7 Smolen JS, Landewé RBM, Bijlsma JWJ et al. EULAR recommendations for the management of rheumatoid arthritis with synthetic and biological disease-modifying antirheumatic drugs: 2019 update. Ann Rheum Dis 2020; 79:685-699.

8 Combe B, Rincheval N. Early lessons from the recentonset rheumatoid arthritis cohort ESPOIR. Joint Bone Spine 2015;82:13-7.

9 Combe B, Rincheval N, Benessiano J et al. Five-year favorable outcome of patients with early rheumatoid arthritis in the 2000s: data from the ESPOIR cohort. J Rheumatol 2013;40:1650-7.

10 Roubille C, Rincheval N, Dougados M et al. Seven-year tolerability profile of glucocorticoids use in early rheumatoid arthritis: data from the ESPOIR cohort. Ann Rheum Dis 2017;76:1797-802.

11 Combe B, Benessiano J, Berenbaum F et al. The ESPOIR cohort: a ten-year follow-up of early arthritis in France: methodology and baseline characteristics of the 813 included patients. Joint Bone Spine 2007;74:440-5.

12 van der Goes MC, Jacobs JWG, Boers $M$ et al. Patient and rheumatologist perspectives on glucocorticoids: an exercise to improve the implementation of the European League Against Rheumatism (EULAR) recommendations on the management of systemic glucocorticoid therapy in rheumatic diseases. Ann Rheum Dis 2010;69:1015-21.

13 Robins JM, Hernán MA, Brumback B. Marginal structural models and causal inference in epidemiology. Epidemiology 2000;11:550-60.

14 Brookhart MA, Schneeweiss S, Rothman KJ et al. Variable selection for propensity score models. Am J Epidemiol 2006;163:1149-56.

15 Ruyssen-Witrand A, Fautrel B, Saraux A, Le-Loët X, Pham T. Infections induced by low-dose corticosteroids in rheumatoid arthritis: a systematic literature review. Joint Bone Spine 2010;77:246-51

16 Roubille C, Richer V, Starnino T et al. The effects of tumour necrosis factor inhibitors, methotrexate, nonsteroidal anti-inflammatory drugs and corticosteroids on cardiovascular events in rheumatoid arthritis, psoriasis and psoriatic arthritis: a systematic review and metaanalysis. Ann Rheum Dis 2015;74:480-9.

17 Da Silva J. A P, Jacobs JWG, Kirwan JR et al. Safety of low dose glucocorticoid treatment in rheumatoid arthritis: 
18 Hwang YG, Saag K. The safety of low-dose glucocorticoids in rheumatic diseases: results from observational studies. Neuroimmunomodulation 2015;22:72-82.

19 Santiago T, da Silva JAP. Safety of low- to mediumdose glucocorticoid treatment in rheumatoid arthritis: myths and reality over the years. Ann N Y Acad Sci 2014;1318:41-9.

20 Ravindran V, Rachapalli S, Choy EH. Safety of mediumto long-term glucocorticoid therapy in rheumatoid arthritis: a meta-analysis. Rheumatol 2009;48:807-11.

21 Goekoop-Ruiterman YPM, de Vries-Bouwstra JK, Allaart $\mathrm{CF}$ et al. Clinical and radiographic outcomes of four different treatment strategies in patients with early rheumatoid arthritis (the BeSt study): a randomized, controlled trial. Arthritis Rheum 2005;52:3381-90.

22 Verschueren P, De Cock D, Corluy L et al. Effectiveness of methotrexate with step-down glucocorticoid remission induction (COBRA Slim) versus other intensive treatment strategies for early rheumatoid arthritis in a treat-totarget approach: 1-year results of CareRA, a randomised pragmatic open-label superiority trial. Ann Rheum Dis 2017;76:511-20.

23 Stouten V, Westhovens R, Pazmino S et al. Effectiveness of different combinations of DMARDs and glucocorticoid bridging in early rheumatoid arthritis: two-year results of CareRA. Rheumatol 2019;58:2284-94.

24 Safy M, Jacobs JWG, IJff ND et al. Long-term outcome is better when a methotrexate-based treatment strategy is combined with $10 \mathrm{mg}$ prednisone daily: follow-up after the second Computer-Assisted Management in Early Rheumatoid Arthritis trial. Ann Rheum Dis 2017;76: 1432-5.

25 Ajeganova S, Svensson B, Hafström I, BARFOT Study Group. Low-dose prednisolone treatment of early rheumatoid arthritis and late cardiovascular outcome and survival: 10-year follow-up of a 2-year randomised trial. BMJ Open 2014;4:e004259.

26 Dixon WG, Abrahamowicz M, Beauchamp M-E et al. Immediate and delayed impact of oral glucocorticoid therapy on risk of serious infection in older patients with rheumatoid arthritis: a nested case-control analysis. Ann Rheum Dis 2012;71:1128-33.

27 Dixon WG, Suissa S, Hudson M. The association between systemic glucocorticoid therapy and the risk of infection in patients with rheumatoid arthritis: systematic review and meta-analyses. Arthritis Res Ther 2011;13: R139.

28 Davis JM, Maradit Kremers $\mathrm{H}$, Crowson CS et al. Glucocorticoids and cardiovascular events in rheumatoid arthritis: a population-based cohort study. Arthritis Rheum 2007;56:820-30.

29 van Sijl AM, Boers M, Voskuyl AE, Nurmohamed MT. Confounding by indication probably distorts the relationship between steroid use and cardiovascular disease in rheumatoid arthritis: results from a prospective cohort study. PloS One 2014;9:e87965. 